\title{
Correction to: Circumstances and causes of sudden circulatory arrests in the Dutch province of Limburg and the involvement of citizen rescuers
}

\author{
R. W. M. Pijls ${ }^{1}$ - P. J. Nelemans ${ }^{2}$ - B. M. Rahel ${ }^{3}$ A. P. M. Gorgels ${ }^{1}$ \\ Published online: 30 January 2018 \\ (c) The Author(s) 2018. This article is an open access publication.
}

\section{Correction to:}

\section{Neth Heart J 2017}

https://doi.org/10.1007/s12471-017-1057-1

In the version of the article originally published online, there was an error in the last section of the Discussion. It is stated that 'In $42 \%$ of the OHCAs a volunteer alert would have been appropriate, but the alert system was not activated.'

The line should have read: 'In 49\% of the OHCAs a volunteer alert would have been appropriate, but the alert system was not activated.'

In the Results it is stated that 'Basically, there were no differences in the distribution of causes between the activated and non-activated group'.

This sentence should have read: 'Within the subgroups with cardiac cause versus non-cardiac cause, there were no differences in the distribution of causes between the activated and non-activated group.'
The online version of the original article can be found under https://doi.org/10.1007/s12471-017-1057-1.

\section{R. W. M. Pijls}

ruud.pijls@mumc.nl

1 Department of Cardiology, CAPHRI school for Public Health and Primary Care, Maastricht University Medical Centre+, Maastricht, The Netherlands

2 Department of Epidemiology, CAPHRI school for Public Health and Primary Care, Maastricht University Medical Centre+, Maastricht, The Netherlands

3 Department of Cardiology, Viecuri Medical Centre for Northern Limburg, Venlo, The Netherlands
Open Access This article is distributed under the terms of the Creative Commons Attribution 4.0 International License (http:// creativecommons.org/licenses/by/4.0/), which permits unrestricted use, distribution, and reproduction in any medium, provided you give appropriate credit to the original author(s) and the source, provide a link to the Creative Commons license, and indicate if changes were made. 


\title{
Advertisement placed here.
}

\author{
SCS bohn \\ stafleu \\ CL van loghum \\ Springer Media
}

Houten 2018 